\section{Determination of Hammett Sigma Constants by Intramolecular Hydrogen Bonding}

THE extensive literature that exists concerning Hammett's $\sigma$-constants has been subjected to several recent reviews, including a compilation and examination of available data ${ }^{1}$, a discussion of the significance and limitations of the concepts involved and an attempt to deduce best values and probable errors for the $\sigma$-values ${ }^{3}$. In most cases $\sigma$-values have been determined by examination of equilibrium constants or reaction-rate constants of substituted benzene derivatives, thus requiring consideration of product states or transition states. In the few instances where examination of the native (unreacted) molecule has led to a determination of $\sigma$ (via physical measurements), the site examined has invariably been attached directly to the ring carrying the groups under study, thereby still exerting some influence (other than electronic) on the effect measured as well as excluding the ortho-position for steric reasons.

\begin{tabular}{|c|c|c|c|}
\hline $\begin{array}{l}\text { Substituent } \\
(\text { ring } B)\end{array}$ & $\sigma$-ortho & $\sigma-m e t a$ & $\sigma-p a r a$ \\
\hline $\mathrm{F}$ & $+0 \cdot 17(a)$ & $\begin{array}{l}+0.31(a) \\
+0.337\end{array}$ & $\begin{array}{l}+0.15(a) \\
+0.062\end{array}$ \\
\hline $\mathrm{Cl}$ & $+0.22(a)$ & $\begin{array}{l}+0.38(a) \\
+0.373\end{array}$ & $\begin{array}{l}+0.20(a) \\
+0.17(b) \\
+0.227\end{array}$ \\
\hline $\mathrm{Br}$ & & & $\begin{array}{l}+0.25(a) \\
+0.24(b) \\
+0.232\end{array}$ \\
\hline $\mathrm{CH}_{3}$ & $-0 \cdot 14(a)$ & $\begin{array}{l}-0.07(a) \\
-0.069\end{array}$ & $\begin{array}{l}-0.14(a) \\
-0.170\end{array}$ \\
\hline $\mathrm{NO}_{2}$ & & $\begin{array}{l}+0.75(a) \\
+0.710\end{array}$ & +0.778 \\
\hline $\mathrm{OH}$ & * & $\begin{array}{l}+0.05(a) \\
+0.121\end{array}$ & $\begin{array}{l}-0.32(a) \\
-0.37\end{array}$ \\
\hline $\mathrm{OCH}_{3}$ & $-0.34(a)$ & $\begin{array}{l}+0.04(a) \\
+0.11\end{array}$ & $\begin{array}{l}-0.28(a) \\
=0.27(b) \\
-0.268\end{array}$ \\
\hline $\mathrm{N}\left(\mathrm{CH}_{3}\right)_{2}$ & & & $\begin{array}{l}-0.80(a) \\
=0.91(b) \\
-0.83\end{array}$ \\
\hline
\end{tabular}

Values $(a)$ obtained with ring $A$ unsubstituted, with carbon tetrachloride as solvent $(K=0.033)$. Values (b) obtained with a $4-\mathrm{NO}_{2}$ group in ring $A$, with methylchloride as solve

Unmarked values are from ref. 3 for comparison. ring $B$ pherolic hydroxy group.

A method has been devised which permits estimation of the Hammett $\sigma$-constant in a manner circumventing many of these objections. In the system:

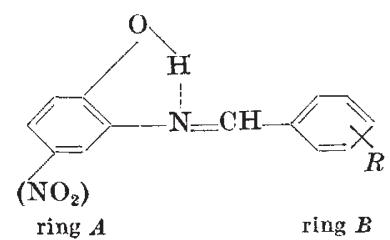

the group being investigated $(R)$ is physically isolated from the $\mathrm{O}-\mathbf{H} \cdots \mathrm{N}$ hydrogen bond regardless of its position on ring $B$. Its effect on the basicity of the nitrogen may be measured, none the less, by the strength of the hydrogen bond on the phenol group of ring $A$ as determined by the exact frequency of the $\mathrm{O}-\mathrm{H}$ stretching vibration. Table 1 shows various $\sigma$-constants obtained from the expression:

$$
\sigma=\Delta \nu_{\mathrm{OH}} \cdot K
$$

where $\Delta v_{\mathrm{OH}}$ is the frequency shift of the substituted homologue (in wave-numbers) compared with the unsubstituted parent compound, and $K$ is a factor employed to bring these wave-number shifts into the range of the classic Hammett $\sigma$-values.

The figures above show that when steric effects are eliminated, the ortho and para $\sigma$-constants are nearly the same. A more elaborate discussion of the principles involved, and a description of experimental detail, will be published elsewhere.

A. T. Shulgin

A. W. BAKER

Dow Chemical Company,

Western Division,

P.O. Box 351,

Pittsburg, California. Aug. 5.

${ }^{1} \mathrm{Jaffe}$, H. H., Chem. Rev., 53, 191 (1953).

2 Taft, R. W., "Steric Effeets in Organic Chemistry", 556 〈John Wiley and Sons, New York, 1956).

${ }^{3}$ McDaniel, D. H., and Brown, H. C., J. Org. Chem., 23, 420 (1958).

\section{Surface-active Characteristics of Sodium Anacardate isolated from Cashew Nut Shell Oil}

CAshew nut (Anacardium occidentale Linn.) shell liquid obtained from unroasted shells was found by Stadeler ${ }^{1}$ to consist chiefly of anacardic acid $(A)$ (on heating, this is decarboxylated to cardanol $(B)$ ), a salicylic acid derivative with a long unsaturated sidechain in the position ortho to the carboxyl group, and cardol $(C)$, a resorcinol derivative with a similar sidechain. Smith ${ }^{2}$ showed that the unbranched side-chain consisted of 15 carbon atoms and 2 double bonds; other workers ${ }^{3}$ have shown that the oily liquid is really a mixture of saturated and mono-, di-, and tri-olefinic compounds in proportions that give, on average, about two double bonds per molecule. Although the surface-active properties of the sulphonated shell liquid have already been studied ${ }^{4}$, no thorough investigation has yet been carried out on anacardic acid, which, being an arylalkyl surfactant and a promising bactericidal agent, needs special attention ${ }^{5}$. Results of a preliminary study on sodium anacardate as a surfactant and bactericidal agent are reported here.

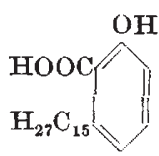

(A)<smiles>Oc1ccccc1</smiles>

(B)

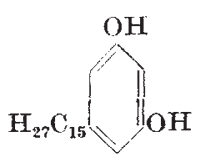

(c)
Shell liquid extracted with 95 per cent ethyl alcohol was saponified and the non-saponifiable material was removed by extraction with ethyl ether. Stage-wise liberation of cardol and then of anacardic acid (followed by separate extractions with ethyl ether), was carried out by passing carbon dioxide and treating the solution with dilute hydrochloric acid respectively. Dark brown anacardic acid, obtained after evaporation of the ether, and purified by charcoal treatment, had the following characteristics : specific gravity $\left(30^{\circ}\right.$ C. $), 1.0001$; refractive index $\left(40^{\circ}\right.$ C. $), 1.5205$; iodine value (Wij, $\left.30 \mathrm{~min}.\right)$ 177.0 (this includes halogen substitution in the aromatic ring); iodine value determined by the corrected method of Kale and Kamath ${ }^{6}, 124 \cdot 4$. On the basis of the average molecular weight of anacardic 